\title{
A note on radar signatures of hydrometeors in the melting layer as inferred from Sentinel-1 SAR data acquired over the ocean
}

\author{
Alpers Werner ${ }^{1,{ }^{*}}$, Zhao Yuan ${ }^{2}$, Mouche Alexis ${ }^{2}$, Chan Pak Wai ${ }^{3}$
}

1 Institute of Oceanography, University of Hamburg, Bundesstrasse 53, 20146 Hamburg, Germany

${ }^{2}$ Laboratoire d'Oceanographie Physique et Spatiale (LOPS), IFREMER, Plouzané 29280, France

${ }^{3}$ Hong Kong Observatory, 134A Nathan Road, Tsim Sha Tsui, Hong Kong

* Corresponding author : Werner Alpers, email address : werner.alpers@uni-hamburg.de

\begin{abstract}
:
Synthetic aperture radar (SAR) images acquired over the ocean often show radar signatures of rain, which are not easy to interpret. The scattering mechanisms causing radar signatures are usually attributed to surface scattering due to sea surface roughness variations caused by raindrops impinging onto the sea surface and/or by up- and downdraft winds. In this paper, we address another radar signature of rain, which is often observed in C-band (and also in X-band) SAR images, but whose origin has been a matter of debate in the ocean remote sensing community since long time and has not been solved yet. This radar signature consists of areas of very high radar backscatter (bright patches) at co- as well as well as at cross-polarization. This paper aims at providing evidence that it is not caused by surface scattering, but by volume scattering from wobbling, non-spherical, oblate hydrometeors within the melting layer. To this end, we first review the theory of radar backscattering from the melting layer as developed by D'Amico et al. (1998) and then present historic radar backscatter data from the melting layer carried out by groundbased and airborne radars, which validate this theory. Then we show four representative Sentinel-1 SAR images acquired over the sea area close to Hong Kong and a SIR-C/X-SAR image acquired over the Gulf of Mexico, which show pronounced radar signatures of rain (bright patches) at co-polarization (VV) and cross-polarization $(\mathrm{VH})$. The analysis of the SAR images yields the result that within the bright patches the ratio of the radar backscatter at cross-polarization to the one at co-polarization shows the same characteristics as the linear depolarization ratio (LDR) measured by radar meteorologist in radar backscattering from the melting layer. Furthermore, we show that radar signatures of rain due to volume scattering may interfere with co-polarization radar signatures of rain due to surface scattering. Thus, cross-polarization SAR images are better suited to detect radar backscattering from the melting layer than co-polarization SAR images, This investigation is of relevance for ocean surface wind retrieval using Cband SARs, since scattering at hydrometeors in the melting layer can cause significant errors in ocean wind retrieval. Areas with simultaneously high co- and cross-polarization NRCS values of around $-10 \mathrm{~dB}$ and $-20 \mathrm{~dB}$, respectively, have to be flagged as areas where the conventional wind retrieval algorithm cannot be applied.
\end{abstract}




\section{Highlights}

- C-band Sentinel-1 SAR images showing radar signatures of rain cells are analyzed. Very strong radar backscattering is observed at co- and cross-polarization. They result from scattering at tilted, oblate hydrometeors in the melting layer. Sentinel-1 SAR data are compared with data from groundbased and airborne radars. Sentinel-1 SAR data are compared with weather radar data from Hong Kong.

Keywords : Rain cells, C-band radar backscatter, Melting layer, Weather radar, Sentinel-1, Crosspolarization, SAR 


\section{1. Introduction}

47 SAR images acquired over the ocean, in particular over coastal areas, often show large 48 variability of the backscattered radar power or the normalized radar cross section (NRCS). This

49 variability can have many reasons: It can be due, among others, to variable sea surface winds, 50 variable the air-sea interface stability, variable ocean surface currents, slick coverage, or rain.

51 Identifying and explaining rain signatures in C-band synthetic aperture radar (SAR) imagery 52 acquired over the ocean is a challenging task, since rain can lead to an increase or a decrease of 53 the NRCS (Braun and Gade, 2006; Alpers et al., 2016). The reason is that several physical 
mechanisms contribute to the rain signature in SAR imagery over the ocean. They are: 1) scattering of the radar pulse from the sea surface, whose roughness is changed by raindrops impinging onto the sea surface, 2) scattering and attenuation from hydrometeors in the atmosphere (volume scattering and attenuation), and 3) scattering from the sea surface whose roughness is modified by rain-related winds, like downdraft or updraft. The first scattering mechanism process is very intriguing since raindrops impinging onto the sea surface can increase the NRCS due to scattering from rain-generated ring waves and from splash products, like stalks, craters, and raindrops emitted from the sea surface. On the other hand, they also can decrease the NRCS roughness due to generation of turbulence, which attenuates the short-scale waves (Bragg waves) responsible for the radar backscattering (Bliven et al., 1993, 1997; Contreras and Plant, 2006; Alpers et al., 2016; Zhang et al., 2016).

One outstanding phenomenon often observed in Sentinel-1 SAR images acquired over the ocean are areas of very high radar backscatter, often referred to as bright patches, which are observed when rain is present. The scattering mechanism causing the bright patches has been a matter of debate in the ocean remote sensing community since long time and has not been solved yet. In the past, several scattering mechanisms have been proposed to explain this phenomenon: 1) Scattering at splash products generated by raindrops impinging onto the sea surface (Atlas, 1994a, 1994b), 2) radar pulse reflection from the sea surface followed by scattering at raindrops above the sea surface (Jameson et al., 1997), 3) scattering at low-salinity "puddles" in the upper ocean layer generated by intense rainfall (Wijesekera and Gregg, 1996), and 4) scattering at steep slopes on the rim of the craters produced by impinging raindrops (Braun, 2003).

In this paper, we compare Sentinel-1 co-and cross-polarization SAR data with data from radar backscattering measurements carried out by ground-based and airborne radars, and we refer to the theory of radar backscattering from the melting layer as developed by d'Amico et 
al. (1998). Since the bright patches in the SAR images show similar characteristics as radar backscattering from the melting layer carried out with ground-based and airborne radars, we conclude that the underlying scattering mechanism is the same, i.e., volume scattering from wobbling, non-spherical, oblate hydrometeors within the melting layer.

The results obtained in this paper are of relevance for ocean surface wind retrieval using Cband SAR data, since scattering at hydrometeors in the melting layer can cause errors in wind retrieval. When inverting NRCS values in SAR images into wind speed, it is assumed that the backscattered radar power is solely due to surface scattering and receives no contribution from volume scattering. Thus, areas with simultaneously high co- and cross-polarization backscatter values due to volume scattering from the melting layer have to be flagged as areas of corrupted winds. We expect that wind retrieval in tropical storms is especially prone to be affected by volume scattering from the melting layer.

The rest of the paper is organized as follows: In Section 2, we review theories and experimental data on radar backsattering from the melting layer. . In Section 3, we present 4 representative examples of co- and cross-polarization Sentinel-1 SAR images on which pronounced radar signatures of rain cells are visible and relate them to quasi-simultaneously acquired weather radar images from the Hong Kong Observatory (HKO). In Section 4, we first present a SIR-C/X-SAR image showing the diversity of radar signatures of rain cells and then show how rain-induced surface scattering can interfere with volume scattering from the melting layer. In Section 5, we interpret the data in terms of a theory.on radar backscattering from hydrometores in the melting layer, and in Section 6, we summarize the results and draw conclusions.

\section{Radar backscattereing from the melting layer}

\subsection{Basics}


The melting layer is the layer in the atmosphere, where the irregularly falling ice particles undergo a phase transition from solid to liquid and where the ice particles are coated with liquid water due to meltin (Szyrmer and Zawadzki, 1999). Here, the radar backscatter or reflectivity (Z) is strongly enhanced, which is the result of complex interactions of dynamics and microphysics as described, e.g., by D'Amico et al. (1998) and Szyrmer and Zawadzki (1999). These authors have shown that, due to the horizontal gradients of the buoyancy in the melting layer, the hydrometeors experience tilting (canting) in the melting layer. Scattering of the radar pulse at randomly oriented (wobbling) melting particles causes the large radar signatures at both, co- and cross-polarization. These theoretical results have been validated by radar backscatter measurements carried out with ground-based radars. Although most ground-based radar backscatter mmeasurements aimed at investigating the melting layer have been carried out at co-polarization (see, e.g., Brandes and Ikeda, 2004; Boodoo et al., 2010; Kumjian, 2013), some measurements were also carried out at cross-polarization.

As early as 1952, Browne and Robinson (1952) performed cross-polarization measurement with a ground-based radar having a wavelength of $3.2 \mathrm{~cm}$. They found that, at crosspolarization, the backscattered radar power from the "melting layer" was larger than the one from raindrops below and snowflakes above the freezing level. Sometimes, they could detect the melting layer only at cross-polarization, but not at co-polarization.

When dealing with detection of melting layers by radars, the following parameters are commonly used by radar meteorologists to determine geometrical and dynamical properties of the hydrometeors.: 1) horizontal reflectivity $\left.\left(\mathrm{Z}_{\mathrm{HH}}\right), 2\right)$ vertical reflectivity $\left.\left(\mathrm{Z}_{\mathrm{VV}}\right), 3\right)$ crosspolarization reflectivity $\left(\mathrm{Z}_{\mathrm{HV}}\right.$ and $\left.\mathrm{Z}_{\mathrm{VH}}\right)$, 4) differential reflectivity (ZDR), 5) linear depolarization ratio (LDR), and 6) cross-correlation coefficient ( $\rho \mathrm{VH}$ and $\rho \mathrm{HV})$.

ZDR, $\rho \mathrm{VH}$, and LDR are defined as follows: 


$$
\mathrm{ZDR}=10 \log _{10}\left(\mathrm{Z}_{\mathrm{HH}} / \mathrm{Z}_{\mathrm{VV}}\right)
$$

$$
\rho \mathrm{VH}=<\mathrm{Z}_{\mathrm{VV}} \mathrm{Z}_{\mathrm{HH}}>/\left(<\mathrm{ZVV}^{2}><<\mathrm{Z}_{\mathrm{HH}^{2}}>\right)^{1 / 2}
$$

$$
\mathrm{LDR}=10 \log _{10}\left(\mathrm{Z}_{\mathrm{HV}} / \mathrm{Z}_{\mathrm{HH}}\right) \text { or } 10 \log _{10}\left(\mathrm{Z}_{\mathrm{VH}} / \mathrm{Z}_{\mathrm{VV}}\right)
$$

The subscipts attached to $\mathrm{Z}$ denote the polarization; the first subscript denotes the polarization of the transmitted signal, and the second one the polarization of the received signal, $\mathrm{V}=$ vertical polarization, $\mathrm{H}=$ horizontal polarization.

Raindrops have always an oblate shape, i.e., their width is larger than their height and they have similar shapes as pebble stones found on beaches. The differential reflectivity ZDR is primarily an indicator of the shape and size of the hydrometeors. The values of ZDR are positive for scattering from raindrops (typically 1.1 to 1.2 , but can be as large as 5.0 for large raindrops). For scattering from hydrometeors in the melting laye.r, they are also positive, but usually slightly larger than for raindrops, and for scattering from ice hydrometeors they are slightly positive as well as slightly negative (Jameson, 1989). Thus, sometimes the melting layer is not detectable on ZDR images.

On the other hand, the correlation coefficient $(\rho \mathrm{VH})$ is a measure for the similarity of the radar backscatter in $\mathrm{HH}$ and $\mathrm{VV}$ polarizations and thus a measure of how uniformly the scatterers are distributed. As shown by Ryzhkov (2001), $\rho \mathrm{VH}$ is a function of the mean canting angle of the hydrometeors. Its value is normally close to 1.0 for raindrops and snowflakes, but below 0.95 for hydrometeors in the melting layer.

As an example of such measurements, we show in Fig. 1 a ZDR image (Panel a) and a $\rho$ VH image (Panel b), which correspond to the weather radar image depicted in Fig. 8. The melting layer can be identified on the ZDR image (Panel a) as a partially circular band with a ZDR value slightly larger than 1.0 (marked by a black arrow) surrounded by areas with ZDR $=1.0$ representing rain in the inner section of the circular band and snow in the outer section. The 
melting layer can also be identified on the $\rho \mathrm{VH}$ image (Panel b) as a partially circular band of slightly decreased $\rho \mathrm{VH}$ values $(0.92-0.94)$. Note, that in this case the melting layer is best visible in the $\rho \mathrm{VH}$ image.
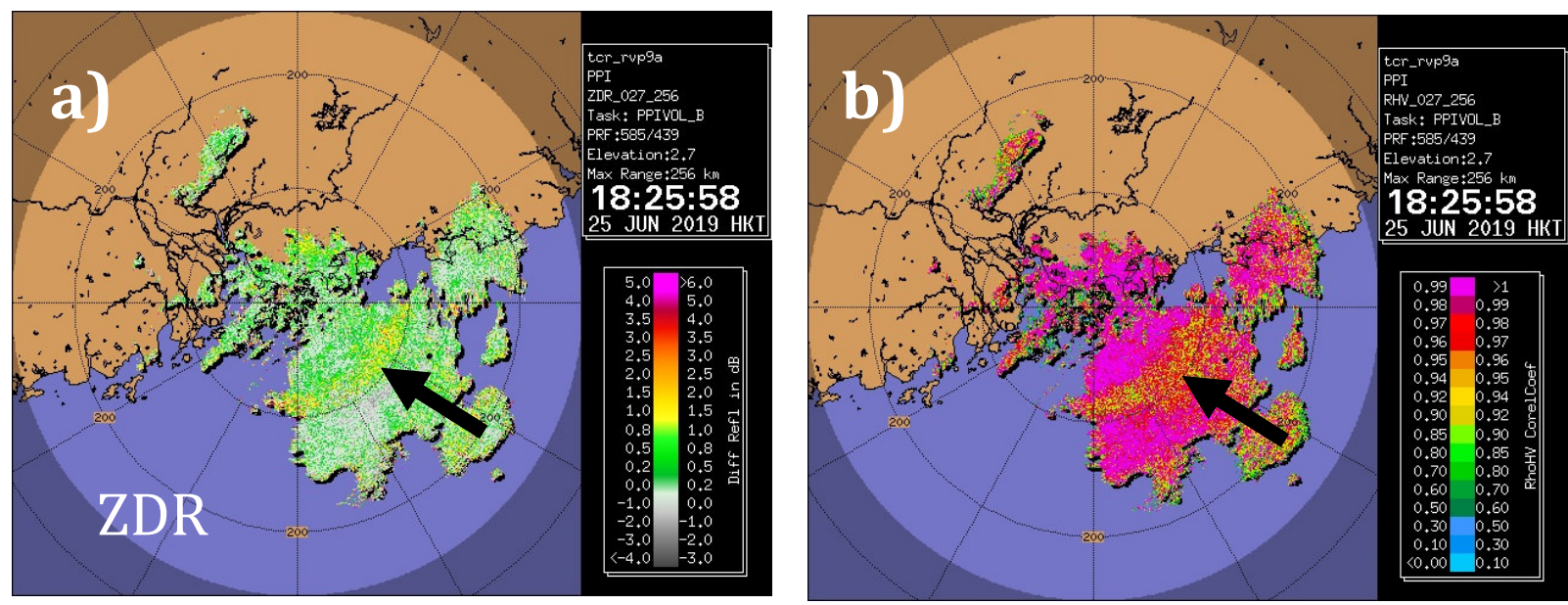

Fig. 1. a) PPI image of the differential reflectivity (ZDR) and (b) the correlation coefficient $(\rho H V)$ acquired by the weather radar of the HKO on 25 June 2019 at 10:25:58 UTC (18:25:58 HKT) quasi-simultaneously with the Sentinel-1A data acquisition at 10:25:07 UTC (Fig. 8). The arrows mark the melting layer as a circular band of slightly increased ZDR values and of slightly decreased $\rho \mathrm{VH}$ values $(0.92-0.94)$,

The height $\mathrm{H}$ of the melting layer can be calculated from the position of the melting layer band visible in the ZDR or the $\rho \mathrm{VH}$ image by applying the relationship

$$
\mathrm{H}=\mathrm{R} \tan \theta+\mathrm{H}_{0},
$$

where $\mathrm{R}$ denotes the distance of the circular melting layer band from the position of the radar, $\theta$ the elevation angle of the radar beam, and $\mathrm{H}_{0}$ the height of the weather station above mean sea level. Applied the radar images depicted in Fig. 8 and using the values $\mathrm{R}=90 \mathrm{~km}, \theta=2.7^{\circ}$, and $\mathrm{H}_{0}=500 \mathrm{~m}$ in Eq. 4, we obtain for the height of the melting layer the value $\mathrm{H}=4.7 \mathrm{~km}$. This lies in the expected range of melting layer heights in this region during strong convective rain events. We have inserted this melting layer height as a red line in Fig. 8, Panel e. LDR is a measure of how much larger the cross-polarization (HV or $\mathrm{VH})$ scattering is compared to the 
co-polarized (HH or VV) scattering. This parameter is not available from the Hong Kong weather radar. At present, operational ground-based radars for weather monitoring provide measurements only at $\mathrm{HH}$ and VV polarizations.

\subsection{Theories of radar backscattering from the melting layer}

Since the diameter of hydrometeors is small (typically $<0.3 \mathrm{~cm}$ ) compared to the wavelength of the Sentinel-1 SAR $(5.4 \mathrm{~cm})$, the Rayleigh scattering theory can be applied (Oguchi, 1983; d'Amico et al., 1998). In early scattering models (Dissanayake and McEvans, 1989: Willis and Heymsfield, 1989), it was assumed that the hydrometeors have a spherical shape. In this case, a horizontally (vertically) transmitted electromagnetic wave generates a purely horizontally (vertically) backscattered electromagnetic wave. Due to the symmetry of the target, all vertical (horizontal) components of the electric field oscillations cancel and ZDR is zero. The increase of backscattered radar power from the melting layer, which is then due purely to the increase of the dielectric constant.

However, the hydrometeors usually have an oblate or a flattened spheroidal shape. They become oblate due to air resistance when falling downwards. In this case, the backscattered

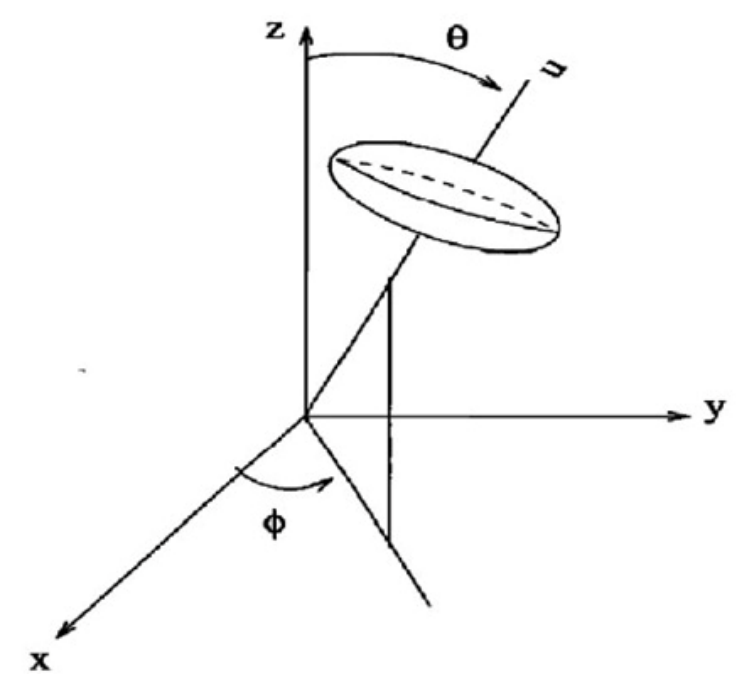


Fig. 2. Orientation of a spheroidal hydrometeor defined by the direction of its axis of symmetry, $\mathbf{u}$. The angles $\theta$ and $\Phi$ denote the canting angle and the azimuth angle, respectively. Reproduced from D'Amico et al. (1998).

horizontally and vertically polarized radar signals are different and consequently, ZDR is nonzero. When the long axis of the hydrometeor is aligned horizontally, then the electric field oscillations parallel to the long axis dominate and the horizontal backscattered radar signal becomes larger than the vertical one, i.e., ZDR becomes positive (d'Amico et al., 1998). The larger the raindrops, the more oblate they are, and the larger is ZDR. However, a crosspolarized backscattered radar signal can only occur, when the oblate hydrometeors are tilted out of plane of incidence of the transmitted electromagnetic wave (Fig. 2). The tilting of the elongated hydrometeors is particularly strong in the melting layer due to large horizontal gradients of the buoyancy encountered there. Thus, it is tilting, which gives rise to the large cross-polarization radar signature of rain in the melting layer. If there were no tiling or wobbling of the spheroidal hydrometeors, then there would be no cross-polarization signature due to scattering. (However, there might be a small cross-polarization signature due to differential wave attenuation between horizontal and vertical polarizations). Since the cross-polarization NRCS is always smaller than the co-polarization one, LDR is always negative. Typical LDR values for raindrops and ice particles are -25 to $-30 \mathrm{~dB}$ and for melting hydrometeors -10 to $-20 \mathrm{~dB}$ (Houze, 2014).

D'Amico et al. (1998) have carried out detailed modeling of cross-polarization radar backscattering from the melting layer. In their model, the hydrometeors in the melting layer consist of ice and liquid water with varying concentrations depending on their height in the melting layer. The oblate spheroidal hydrometeors are subject to tilting with respect to the horizontal. Using this model, they were able to simulate quite well the profiles shown in Fig. 3. 


\subsection{Ground-based and airborne radar measurements of the melting layer}

In this sub- section, we present data of co-and cross-polarization measurements carried out with a ground-based radar and a nadir looking airborne radar, which confirm the theory presented in the previous section. They show that the melting layer manifests itself not only in an increase of the co-polarized reflectivity (in these examples of $\mathrm{Z}_{\mathrm{HH}}$ ), but also in an increase of the cross-polarization reflectivity. The ground-based measurements were carried out by the fully-polarimetric C-band radar of the German Aerospace Center (DLR) at Oberpfaffenhofen, Germany (D'Amico et al., 1998), and the airborne measurements by the NASA/JPL ABMAR airborne RADAR (Jameson et al., 1997). Radar meteorologists usually do not plot the crosspolarization reflectivity, but the linear depolarization ratio (LDR) defined by Eq. 3, which is the ratio of the reflectivity at cros-polarization to the one at co-polarization or in logarithmic scale, the difference between $10 \log Z_{\mathrm{HV}}$ and $10 \log \mathrm{Z}_{\mathrm{HH}}\left(\right.$ or $10 \log \mathrm{Z}_{\mathrm{VH}}$ and $10 \log \mathrm{Z}_{\mathrm{VV}}$ ), see, e.g., D'Amico et al.,1998. Figs. 3 and 4 show that the reflectivity Z and LDR are strongly enhanced in the melting layer where LDR takes the values are $-18 \mathrm{~dB}$ (Fig. 3) and $-11 \mathrm{~dB}$ (Fig. 4). Note that in both measurements, the peaks in Z and LDR are not collocated, which is a commonly observed phenomenon, but its explanation is beyond the scope of this paper.
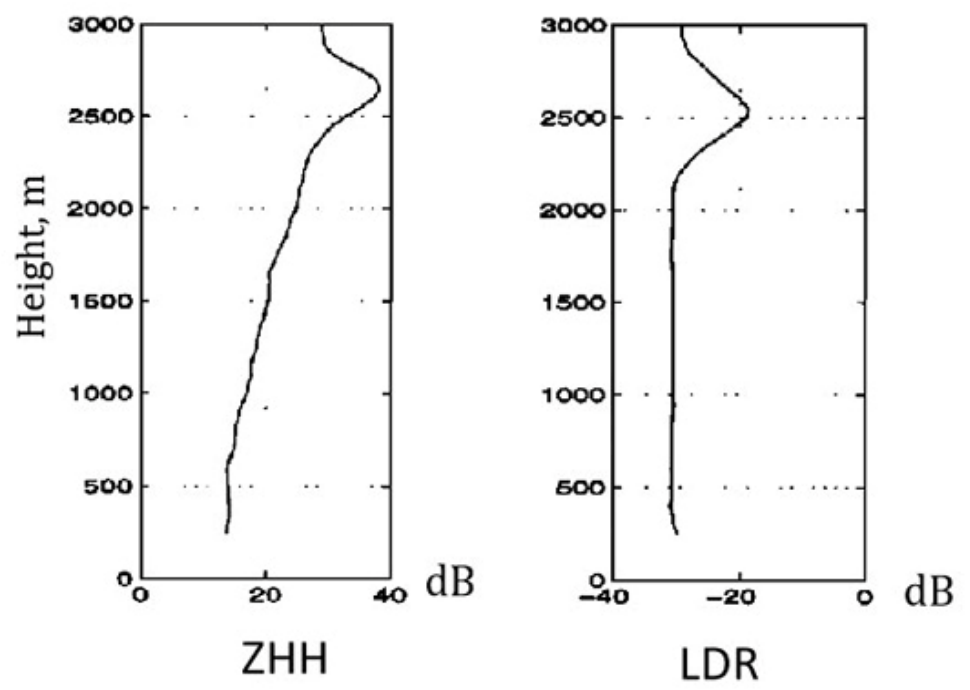
Fig. 3. Vertical profiles (in meters) of $Z_{\mathrm{HH}}$ and LDR measured on 17 August 1994 at 1433 LT by the DLR ground-based radar showing the melting layer in both parameters. The LDR of the melting layer is - $18 \mathrm{~dB}$. Note that the peaks of $Z_{\mathrm{HH}}$ and LDR are not collocated. Reproduced from D'Amico et al. (1998).

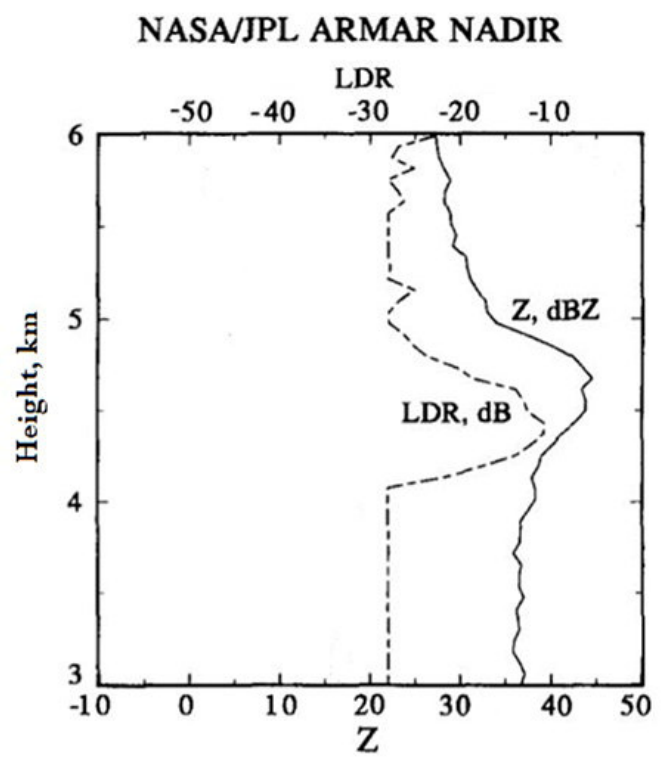

Fig. 4. Vertical profiles of $\mathrm{Z}_{\mathrm{HH}}$ and LDR measured by the NASA/JPL ABMAR airborne radar that flew over a melting layer associated with a forming tropical cyclone in the Tropical Western Pacific in 1993. The LDR of the melting layer is $-11 \mathrm{~dB}$. Adapted from Jameson et al. (1997).

\section{Concurrent Sentinel-1 SAR and weather radar measurements of rain cells}

In this section, we present four representative examples of Sentinel- 1 SAR images showing areas of strong C-band radar backscattering ("bright patches") at co- and crosspolarization and compare them with quasi-simultaneously acquired weather radar data of the HKO. The SAR onboard the Sentinel-1 satellites operates at C-band $(5.4 \mathrm{GHz})$ and has different exclusive acquisition modes. Here we use only SAR images captured in the Interferometric Wide (IW) swath mode at VV and VH polarizations (spatial resolution: $20 \mathrm{~m}$ x $22 \mathrm{~m}$, swath width: $250 \mathrm{~km}$, incidence angle range: $\left.29 \cdot 1^{\circ}-46.0^{\circ}\right)$. All images shown in this section are Level 1 Ground Range Detected (GRD) products provided by ESA via the Copernicus O)pen Access Hub (https://scihub.copernicus.eu). They were acquired during ascending satellite passes with the SAR antenna pointing to the right of the satellite track. 
The Hong Kong (HK) weather radar is a dual-polarization C-band radar with a half-power beam width of 0.5 degrees and has two modes of operation. One is volume scan with scanning at different elevation angles (the lowest one being $\theta=2.7^{\circ}$ ) with a range of $256 \mathrm{~km}$ and a repeat cycle of 6 minutes. The other one is horizontal scan with a range of $512 \mathrm{~km}$ and a repeat cycle of 12 minutes. The $64 \mathrm{~km}$ and $128 \mathrm{~km}$ images are derived from the $256 \mathrm{~km}$ range data. The weather radar takes measurements at $\mathrm{HH}$ and VV polarizations, but not at cross-polarization (VH or HV). Among other products, it provides reflectivity measurements converted into rain rate at a height of $3 \mathrm{~km}$ above mean sea level in the Constant Altitude Plan Position Indicator (CAPPI) display. Furthermore, also Plan Position Indicator (PPI) maps are available in real time, from which vertical cross sections of the reflectivity can be generated on demand. The PPI maps shown Panels e are from the $256 \mathrm{~km}$ range data.

For all four rain events presented in this section (Fig. 5 - Fig. 8), we show in Panels a and b VV- and VH- polarization images captured simultaneously by the Sentinel-1 SAR, in Panel c the reflectivity image of the HK weather radar, in Panel d the profiles of the VV NRCS, VH NRCS values and radar reflectivity values along the transects inserted in Panels $a, b$, and $c$, in Panel e the reflectivity in the range-height indicator (RHI) presentation along transects shown in Panel c together with the $3 \mathrm{~km}$ height line (solid black line) and the zero-degree Celsius height line obtained from radiosonde data (dashed black line), and in Panel $\mathrm{f}$ the wind field as provided by the European Centre for Medium-Range Weather Forecasts (ECMWF). Inserted in Panel $d$ are the VV NRCS and VH NRCS values calculated from the background wind adjacent to the bright patches by using the C-band Geophysical Model function CMOD5n developed by Hersbach (2015) for VV polarization and the one developed by Hwang et al, (2015) for cross-polarization. 


\subsection{The 6 June 2018 rain event}

The SAR images of this event (Fig. 5, Panels a and b) show very pronounced signatures of three rain cells at VV and VH polarization. The increase of NRCS (relative to the ambient area) of the three rain cells is about $9 \mathrm{~dB}$ in $\mathrm{VV}$ and $14 \mathrm{~dB}$ in $\mathrm{VH}$ polarization (Panel d). The VV NRCS and VH NRCS values of the highest peaks are $-10 \mathrm{~dB}$ and $-22 \mathrm{~dB}$, respectively, such that the ratio of VH NRCS to VV NRCS is, in logarithmic scale, $-12 \mathrm{~dB}$. Outside these peaks, the NRCS values lie in the expected range as calculated from the ECMWF wind map using the C-band geophysical model functions (Fig. 5f).

\section{S1A_IW_GRDH_1SDV_20180606T102500_20180606T102529_022235_0267D7_CCF1.SAFE}
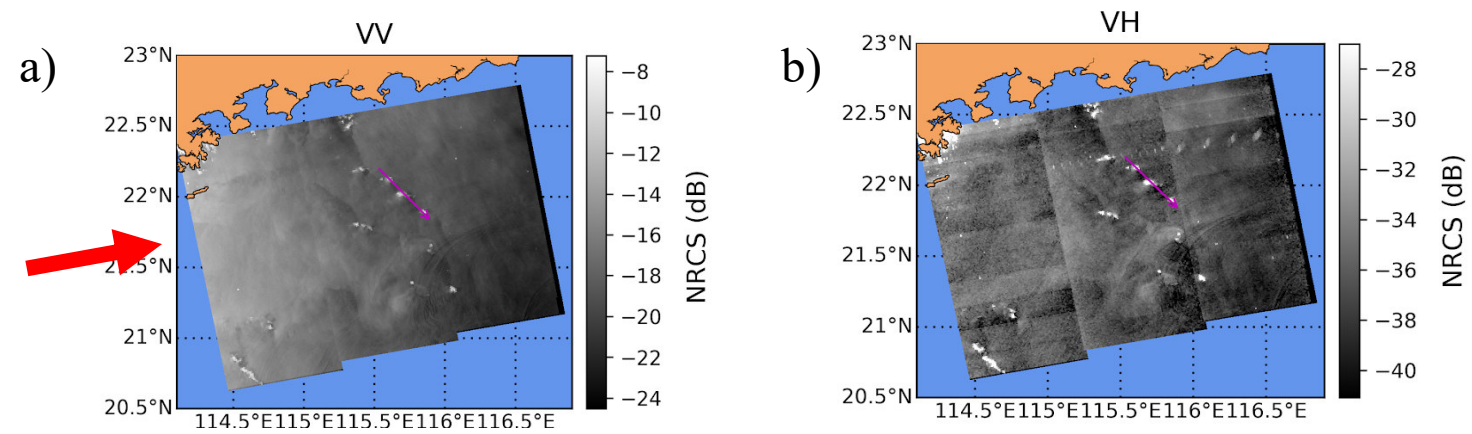

c)

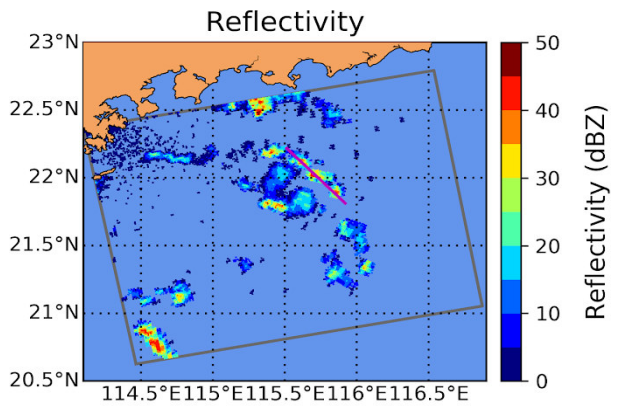

e)

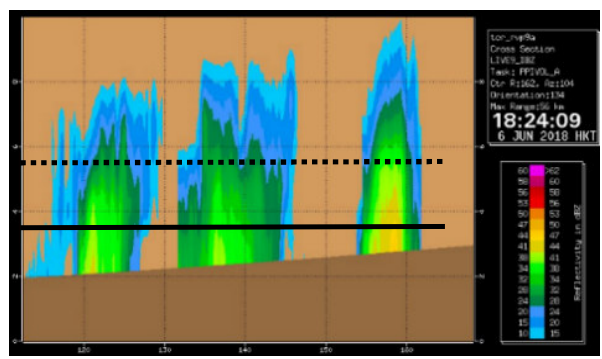

d)
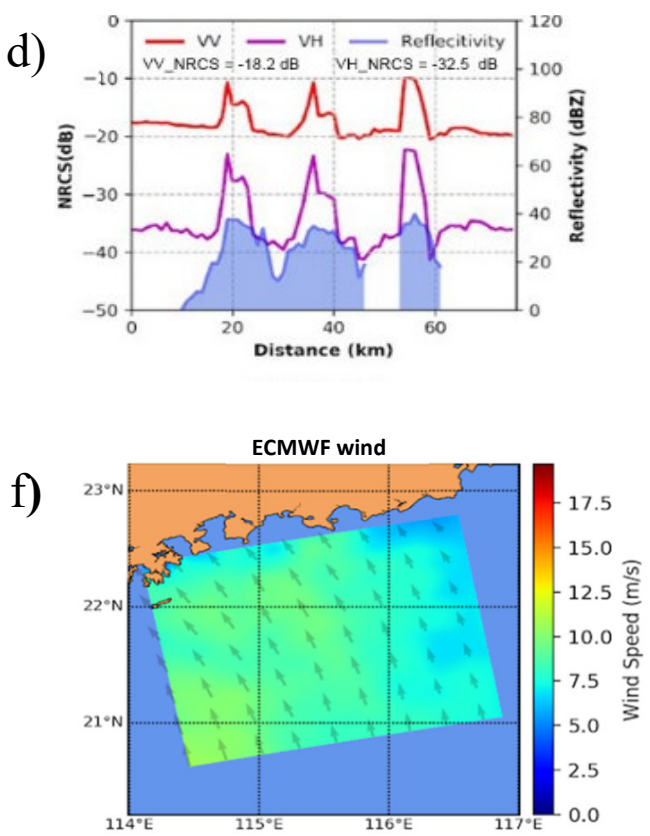
Fig. 5. Sentinel-1 A SAR images acquired on 6 June 2018 at 10:25 UTC at VV (Panel a) and at VH (Panel

294

295

b) over the South China Sea off the Hong Kong coast showing radar signatures of a rain band over the sea. The inserted red lines denote the transects along which the variation of NRCS values was measured. The thick red arrow marks the direction into which the SAR antenna is pointing. Panel $\mathrm{c}$ shows the CAPPI reflectivity image at a height of $3 \mathrm{~km}$ acquired by the HKO weather radar at 10:24 UTC (18:24 Hong Kong Standard Time (HKT)) together with the $3 \mathrm{~km}$ height line (solid black line) and the zero-degree Celsius height line (dashed black line). Panel d shows the variation of NRCS in VV and VH as well as the reflectivity measured by the weather radar along the transects inserted in Panels a and b. Inserted are the VV NRCS and VH NRCS values of the background wind field calculated from the wind map (Panel f). Panel e shows in the range height indicator (RHI) presentation the reflectivity along the transect inserted in Panels a and $\mathrm{b}$, and Panel $\mathrm{f}$ shows the wind field as provided by ECMWF.

\subsection{The 12 April 2017 rain event}

The SAR images of this event (Fig. 6, Panels a and b) show a strong rain band extending in the NE-SW direction, which gives rise to pronounced peaks in the VV NRCS and VH NRCS transects. The VV NRCS and the VH NRCS values of the highest peaks are $-10 \mathrm{~dB}$ and $-22 \mathrm{~dB}$, respectively, such that the ratio of VH NRCS to VV NRCS is, in logarithmic scale, $-12 \mathrm{~dB}$. However, here the heights of the peaks relative to the background are lower than in the previous event caused by higher ambient winds. A noteworthy feature visible in Panel $\mathrm{d}$ is the pronounced dip in the VV NRCS profile to the right (east) of the peak. We interpret it as caused by the decrease of surface scattering due to damping of the short waves (Bragg waves) due to rain-generated turbulence. 


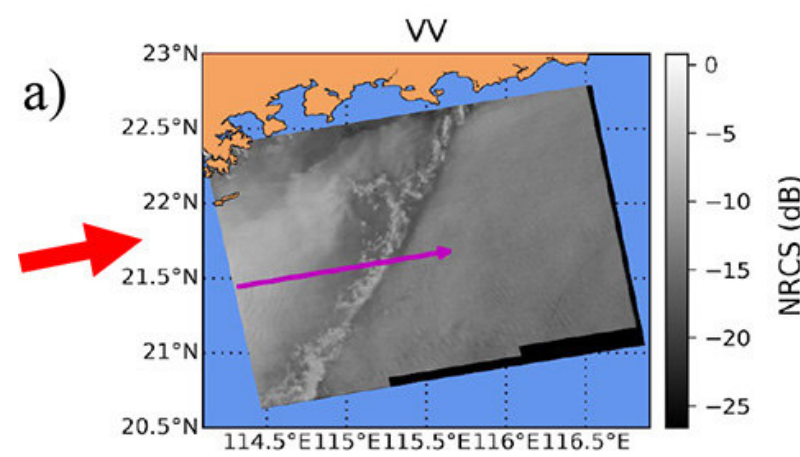

b)

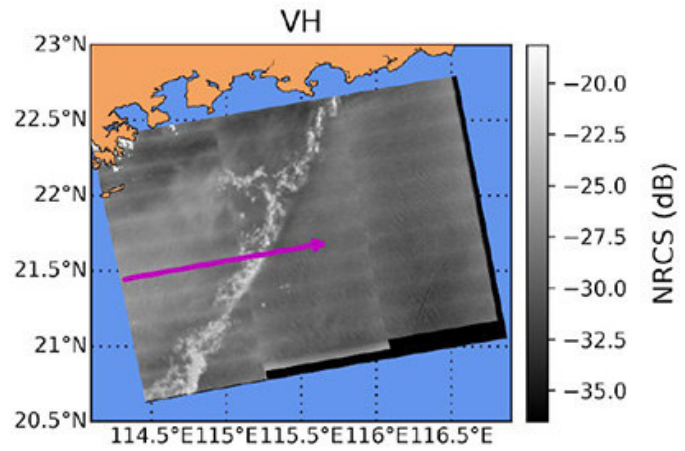

c)

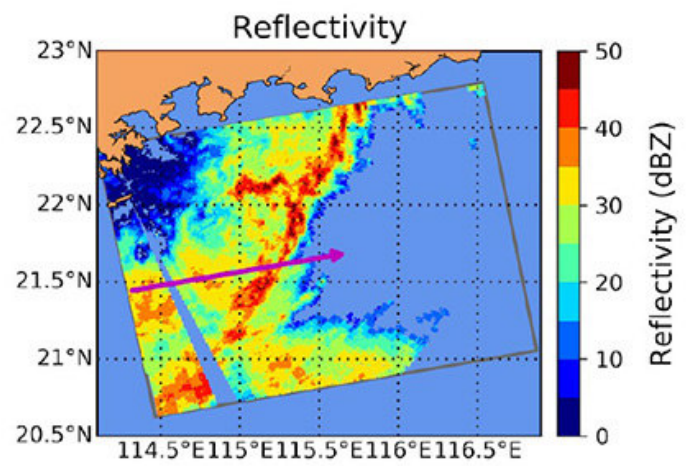

d)

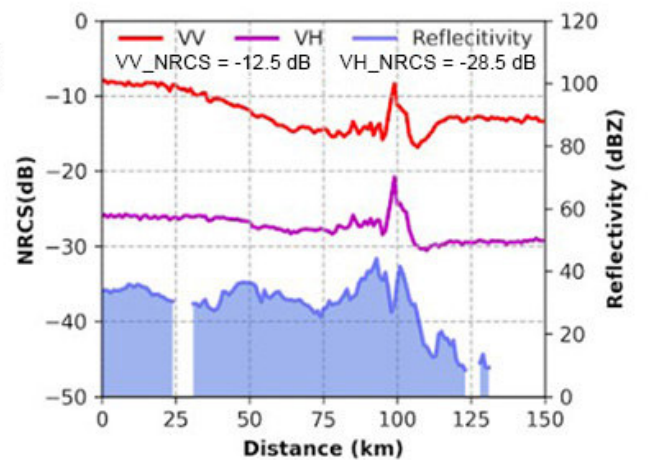

f)

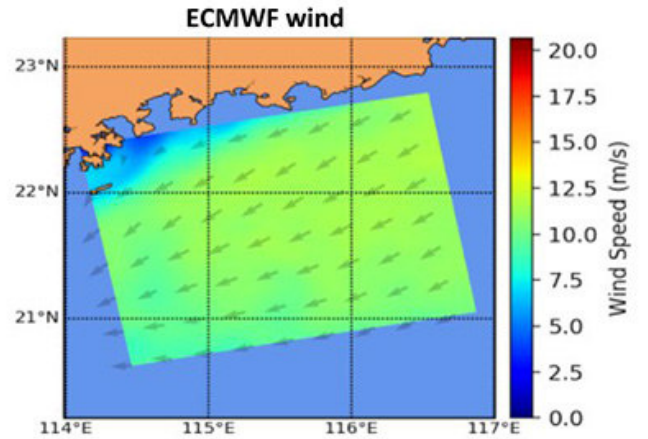

e)

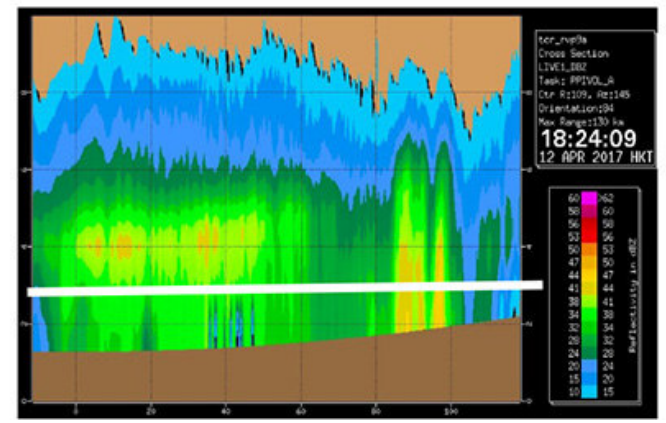

Fig. 6. Same as in Fig. 5, but for 12 April 2017 at 10:25 UTC (Sentinel-1) and 10:24 UTC (weather radar).

\subsection{The 3 September 2017 rain event}

The SAR images of this event (Fig. 7, Panels $a$ and $b$ ) show a strong rain band aligned in the

NW-SE direction, which gives rise to the peaks in the VV and VH NRCS profiles. The VV

NRCS and the VH NRCS values of the highest peaks are $-10 \mathrm{~dB}$ and $-21 \mathrm{~dB}$, respectively, such that the ratio of VH NRCS to VV NRCS is, in logarithmic scale, $-11 \mathrm{~dB}$. Note that the weather radar image (Fig. 7, Panel c) shows also rain to the west of this rain band, but the VV and VH SAR images do not show these strong radar signatures. Here the radar signature of rain 
is solely due to scattering from the sea surface whose roughness is modified by raindrops impinging onto the sea surface.

327

328

329

330

331

Fig. 7. Same as in Fig. 1, but for 3 September 2017 at 10:25 UTC (Sentinel-1) and 10:24 UTC (weather

\section{S1A_IW_GRDH_1SDV_20170903T102458_20170903T102527_018210_01E9AD_COF2.SAFE}

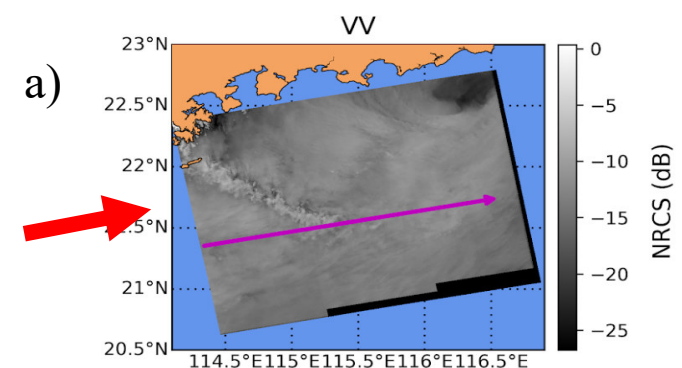

b)

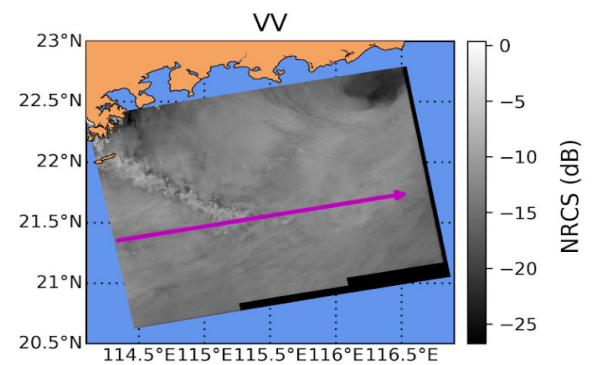

c)

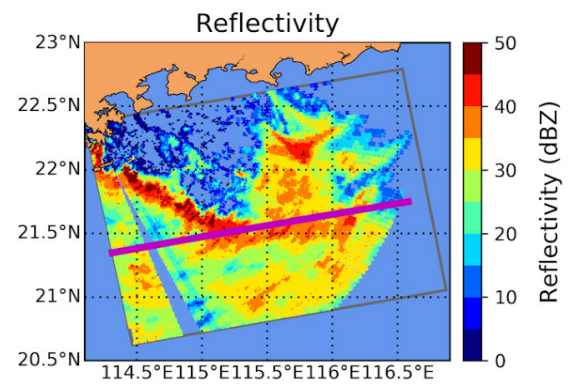

d)

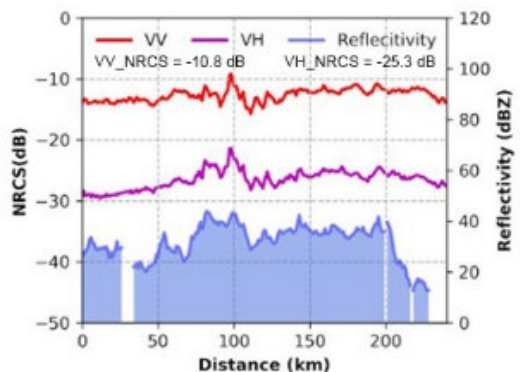

e)
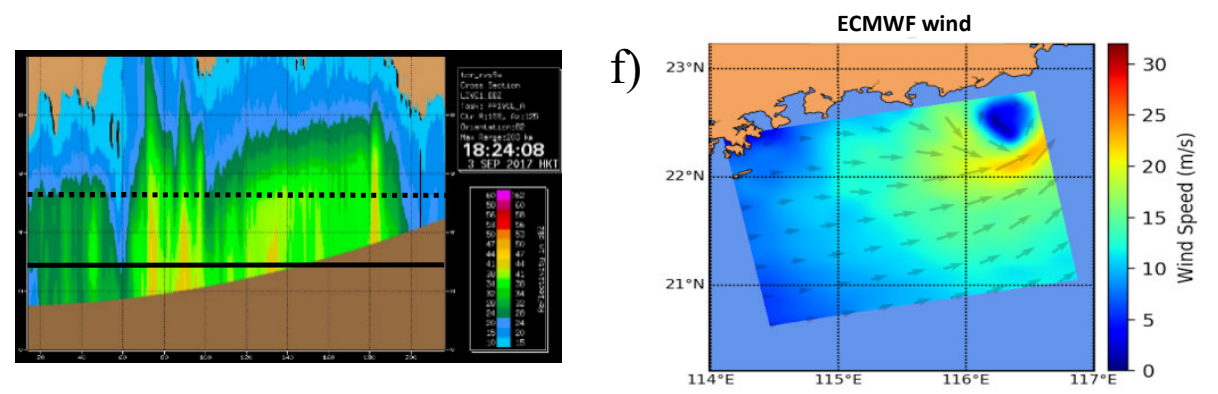

f)

radar). This rain event is associated with the tropical storm Marawar.

3.4. The 25 June 2019 rain event Contrary to the previous SAR images showing rain cells or rain bands, the SAR images of this event (Fig. 8, Panels a and b) show a strong increase of the VV NRCS and VH NRCS values in a large area with interspersed peaks. The VV NRCS and the VH NRCS values of the highest peaks are $-10 \mathrm{~dB}$ and $-23 \mathrm{~dB}$, respectively, such that the 
to retrieve the height of the melting

347

c)
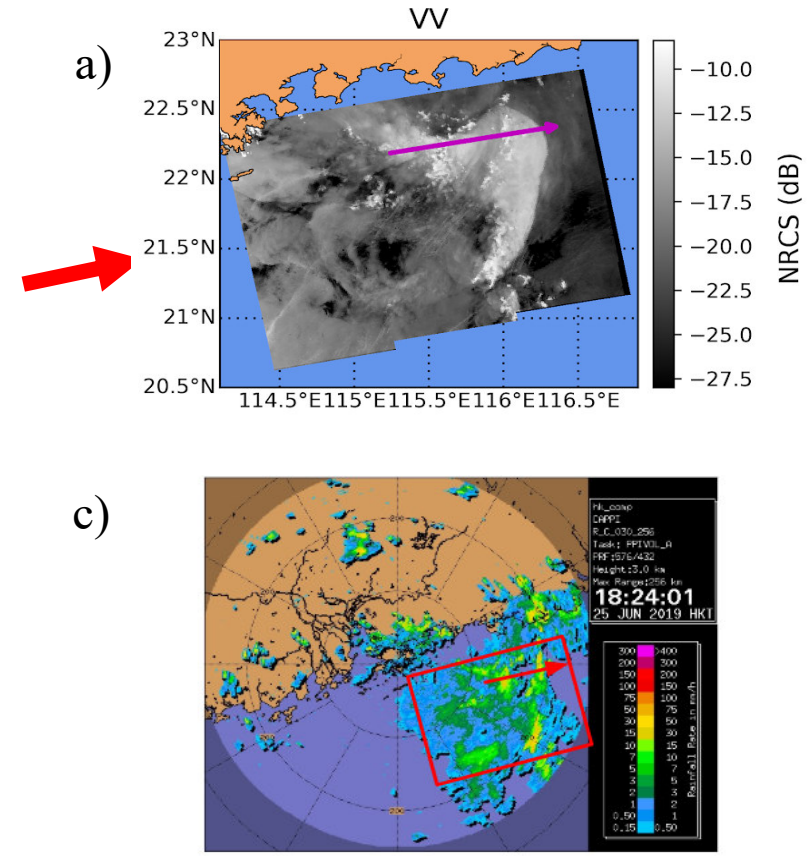

e)

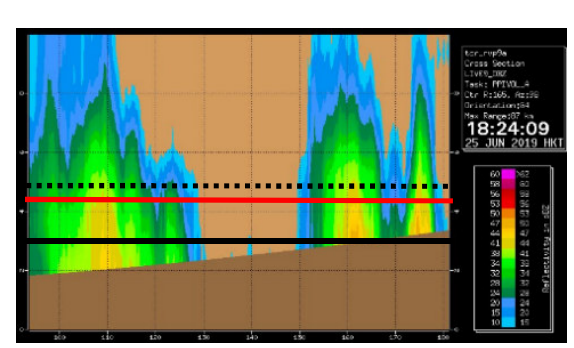

b)

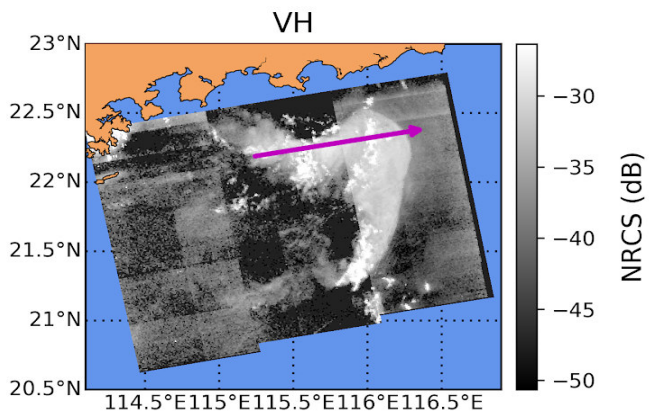

d)

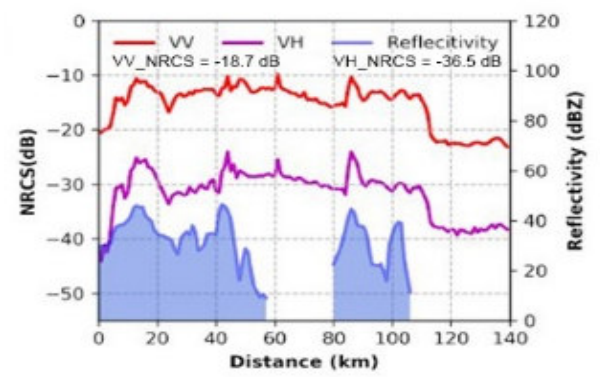

f)

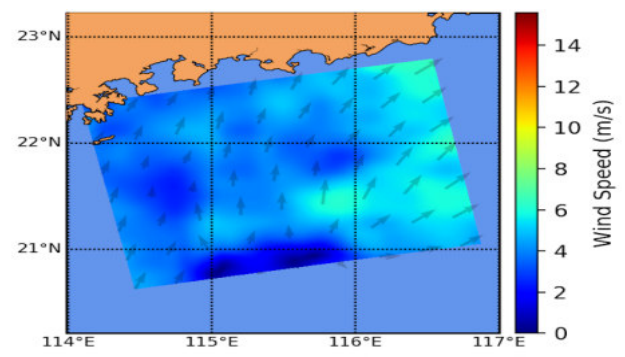

Fig. 8. Same as in Fig. 1, but for 25 June 2019 at 10:25 UTC (Sentinel-1) and 10:24 UTC (weather radar).

The red line inserted in Panel e denotes the height of the melting layer as inferred from the ZHV and $\rho \mathrm{HV}$ images depicted in Fig. 1. Note that the melting layer is located $500 \mathrm{~m}$ below the zero-degree height line. 


\section{Interplay between volume and surface scattering}

As stated before, the backscattered radar signal of Sentinel-1 SAR receives contribution from volume scattering as well as from surface scattering. This can give rise to significant distortions of the theoretically expected radar signature of a rain cells due to volume scattering as evident in the Sentinel-1 SAR image depicted in Fig. 6. To further illustrate this complexity, we show in Fig. 9 simultaneously acquired multi- polarization/multi-polarization SAR images with rain cells from the SIR-C/X-SAR mission in 1994 (Melsheimer, 1998). These images clearly show the strong variability of radar signatures of rain cells with radar frequency and polarization as stated in the Introduction. For L-band, the radar signal penetrates the melting layer almost unattenuated and therefore, the L-band radar signature of the rain cell has its origin almost exclusively in surface scattering. The black patch in the center of the L-band images is due to impinging raindrops, which generate turbulence in the upper ocean layer and attenuate there the L-band Bragg waves. When comparing the C-band VV and HH images with the HV image, we see that rain cells have a higher contrast in the VH image than in the VV and $\mathrm{HH}$ images. The reason is that the background C-band NRCS due to wind-induced surface scattering is in the VH image much smaller than in the VVand $\mathrm{HH}$ images. Furthermore, we also note that for C-band, the size of the bright patch is smaller in the VV and HH images than in the HV image and that there is a small dark patch adjacent to the bright one in the HH/VV images. We interpret it as caused by the superposition of volume scattering and surface scattering: In the bright area, the increase of the NRCS induced by volume scattering at hydrometeors in the melting layer is dominant, and in the dark area, the attenuation of the Bragg waves is dominant due to raingenerated turbulence, thereby inducing the reduction of the NRCS.

Another remarkable feature visible in Fig. 9 is the small bright band located west of the large bright patch in the center, which is visible only in the CHV image, but not in the XVV image nor in the $\mathrm{CVV}$ and $\mathrm{CHH}$ images. We interpret this feature as a radar signature of a small rain 
band in the melting layer, which is less strong than the signature of the large rain cell located in the center of the CHV image (see Fig. $9 \mathrm{f}$ ). This signature is not visible in the $\mathrm{CHH}$ and CVV images, because its NRCS value is much smaller than the NRCS of the background due to high winds. This suggests that cross-polarization is better suited for detecting scattering from the melting layer than co-polarization, because it receives less contribution from surface scattering, and therefore the signal-to-noise ratio is higher. Note, that this small rain band is also visible in the L-band $\mathrm{VV} / \mathrm{HH}$ images as a faint dark band, which has its origin in the damping of Bragg waves by the rain-generated turbulence.
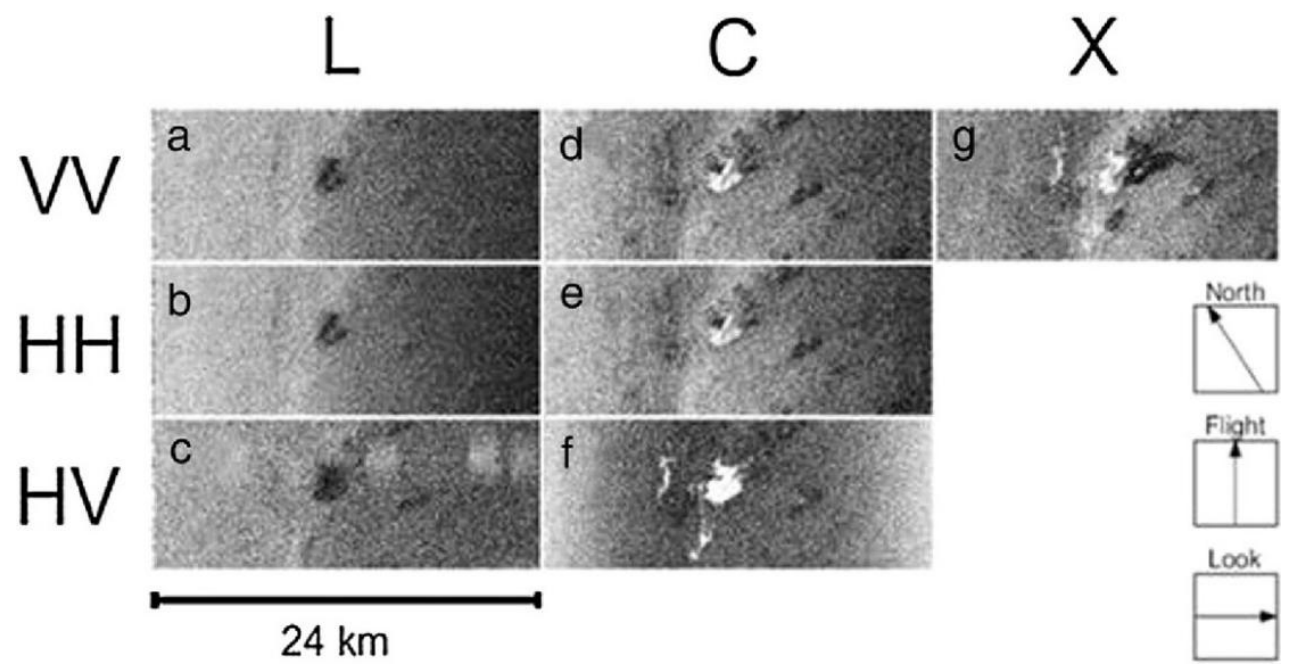

Fig. 9. SIR-C/X-SAR images acquired at L-, C-, and X-band simultaneously over the Gulf of Mexico at 08:11 UTC on 18 April 1994, displaying the strong dependence of the radar signature on radar frequency and polarization (reproduced from Alpers et al., 2016). Note, in particular, the difference in the rain signature patterns of the rain cell in the $\mathrm{CVV} / \mathrm{CHH}$ and $\mathrm{CVH}$ images, which are due to superposition of volume and surface scattering in the CVV and CHH images.

Fig. 10 a shows a zoom of the CVH image depicted in Fig. 9 f with a transect line inserted along which the ratios HV NRCS/HH NRCS and VH NRCS/VH NRCS, termed LDRsAR (see

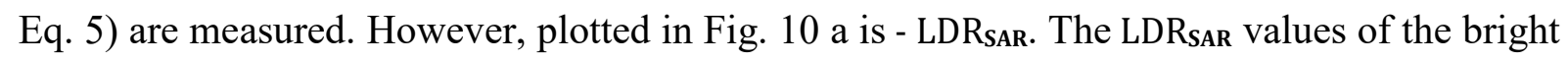


patch are $-15 \mathrm{~dB}$ for $\mathrm{HV} / \mathrm{HH}$ and $-16 \mathrm{~dB}$ for $\mathrm{VH} / \mathrm{VV}$. This shows that $\mathrm{LDR}_{\text {SAR }}$ depends very

412 little on the polarization of the incident pulse.

413

414

415

416

417

418

419

420

421

422

423

424

425

426

427

428

429

430

431

432

433

434

435

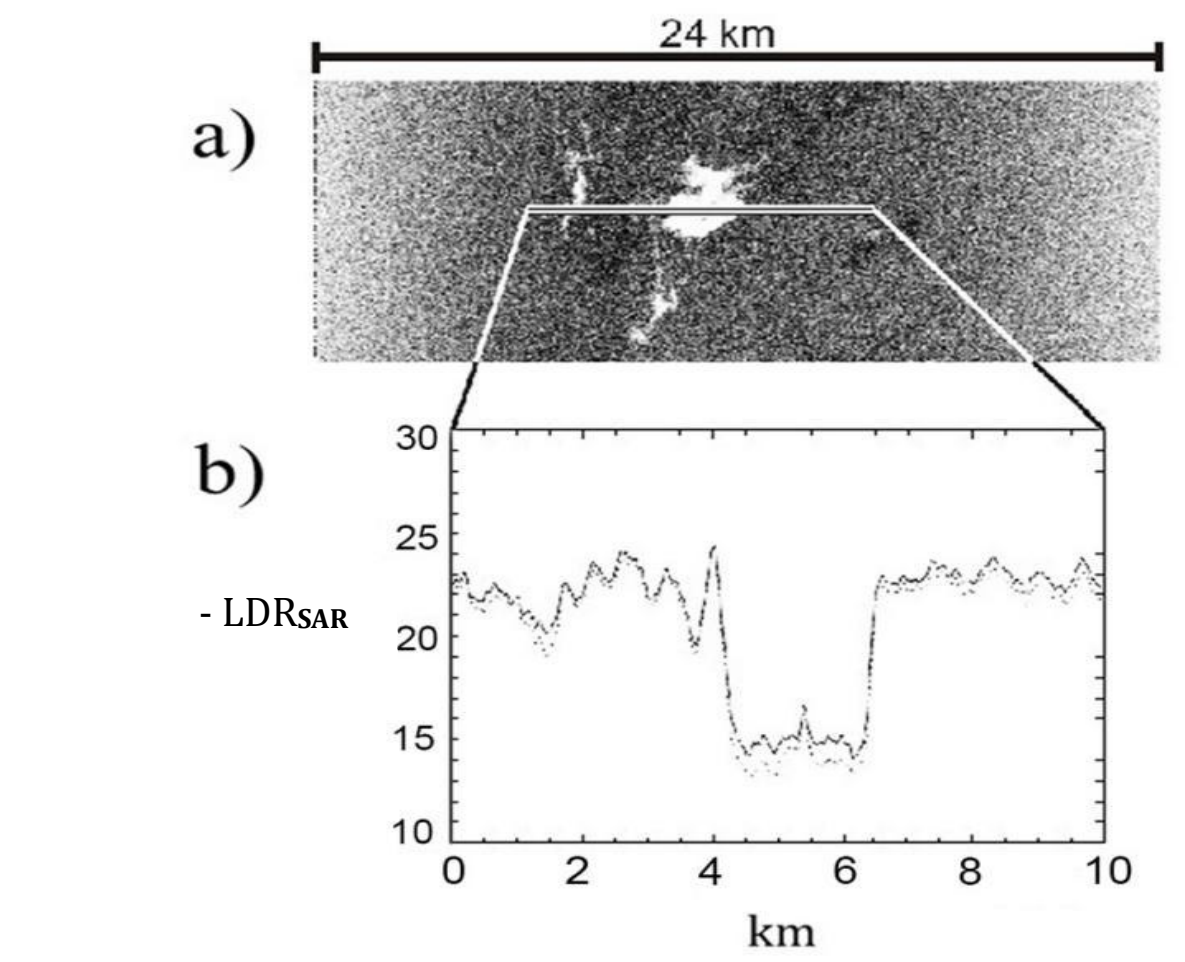

Fig. 10. a) Section of the CHV SAR image shown in Fig. 9 f; b) Ratio of the NRCS values at HH and HV polarizations (solid line), and at VV and VH polarizations (dashed line). Reproduced from Braun (2003).

Panel a of Fig. 11 shows schematically how a rain cell is imaged when volume scattering and rain-related surface scattering are involved, Panel $b$ shows the backscattered radar pulse due to volume scattering from hydrometeors in the melting layer and Panel $\mathrm{c}$ the one due to surface scattering, where, in this case, the backscattered radar power is reduced due to damping of the Bragg waves by rain-induced turbulence. For co-polarization, often both scattering mechanisms contribute such that the backscattered pulse attains the form shown in Panel d. For crosspolarization, rain-related surface scattering contributes only very little to the total radar backscattering, such that the backscattered pulse attains the form shown in Panel b. This 
scattering geometry applies to the rain event of 12 April 2017 (Section 3.2,) where, in the VV image (Fig. 6 a), the radar signature of the rain band consists of a bright band followed by a dark band, while in the VH image it consists only of a bright band, see also the NRCS profiles depicted in Fig. 6 d.

Antenna look direction
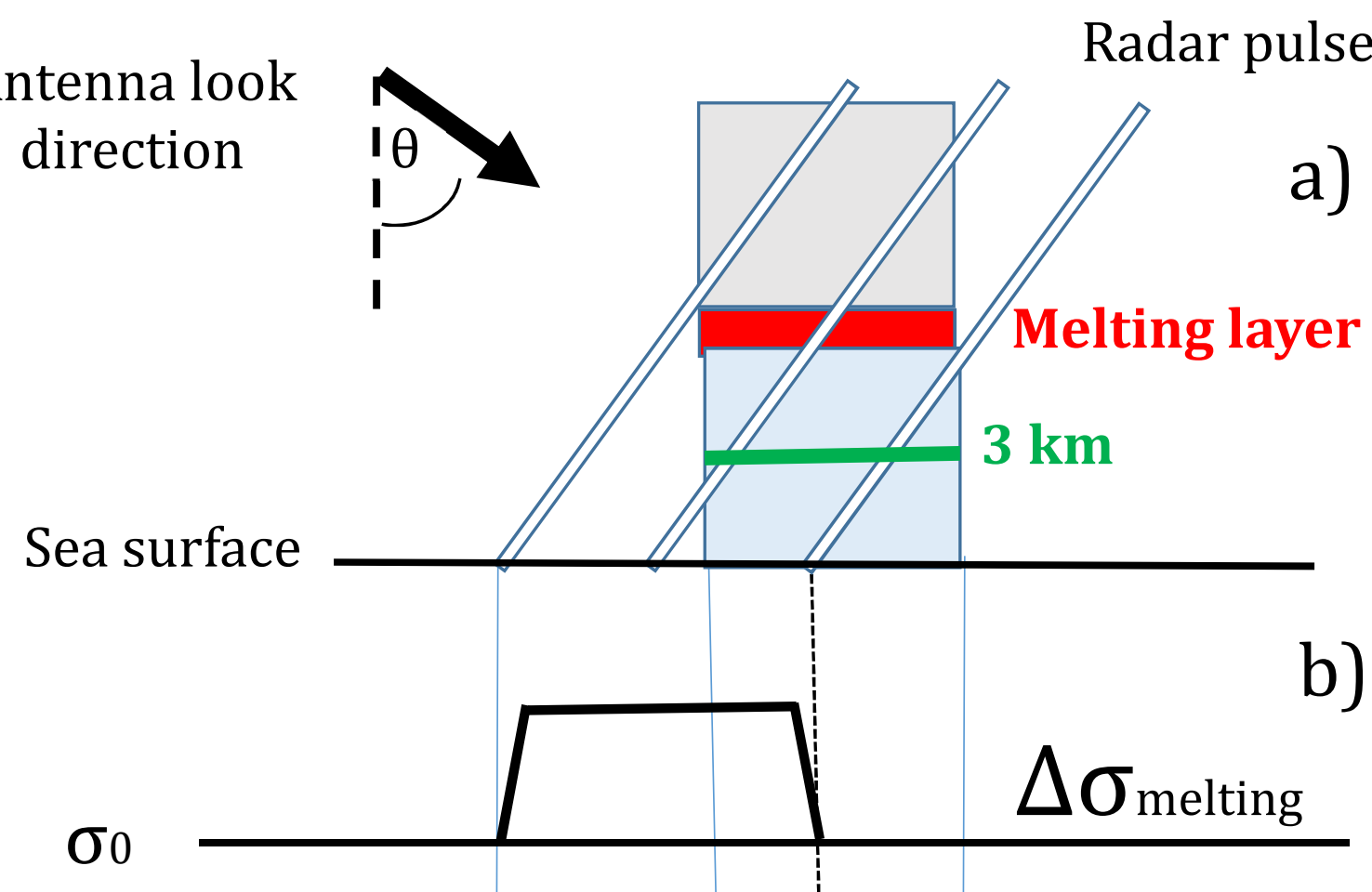

Melting layer

\section{$3 \mathrm{~km}$}

b)

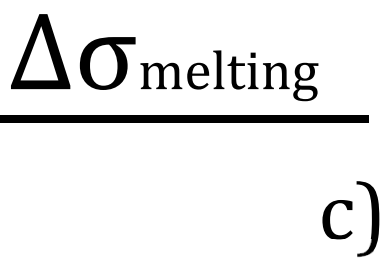

$\Delta \sigma_{\text {surface }}$

d)

Fig. 11. a) Scattering geometry of a rain cell imaged by SAR with look direction from the left. The red rectangle denotes the melting layer and the green line denotes the height at which the weather radar 
measures the reflectivity, b) Form of the backscattered radar pulse due to volume scattering from the melting layer. c) Form of the backscattered radar pulse due to rain-modified surface scattering, which, in this case, is reduction of the backscattered radar power due to wave damping by rain-generated turbulence.

d) Form of the backscattered radar pulse due to both effects. The inset $\sigma_{0}$ denotes the background backscattered radar power and $\Delta \sigma$ the deviation from the background.

\section{Interpretation of the data}

The analysis of the quasi-simultaneously acquired Sentinel-1 SAR images and weather radar data presented in Section 3 show that the bright patches visible in the Sentinel-1 SAR images are related to rain cells (Fig. 5), rain bands Figs. 6 and 7), or larger rain areas (Fig. 8). Note that the weather radar images depicted in the Panel c of Figs. $5-8$ show the radar reflectivity at a height of $3 \mathrm{~km}$, while the melting layer lies above this height. The height of the melting layer can be estimated from the height of the zero- degree level, which usually is located few hundred meters higher than the the center of the melting layer. In one case, in the 25 June 2019 event (Section 3.4), we were able to deternine the height of the melting layer from weather radar data of the HKO (see ZHV and $\rho \mathrm{HV}$ images depicted in Fig. 1). Panels e of Figs. $5-8$ show that during all four rain events hydrometeors were present in the melting layer. Panels d of Figs. 5 - 8 show that the peaks in the VV NRCS and VH NRCS profiles are highly correlated. In addition, peaks in the SAR NRCS profiles are also correlated reasonably well with peaks in the reflectivity profiles obtained from CAPPI weather radar data. (Note, that the radar signatures of the rain cells in the Sentinel-1 SAR images and in the CAPPI displays refer to different heights, i.e., the melting layer height and the $3 \mathrm{~km}$ height, respectively). Furthermore, the height of the peaks relative to the background is always higher at $\mathrm{VH}$ polarization than at $\mathrm{VV}$ polarization. The VV NRCS peak values range from $-9 \mathrm{~dB}$ to $-10 \mathrm{~dB}$, and the VH NRCS peak values from $-20 \mathrm{~dB}$ to $-24 \mathrm{~dB}$. 
In order to prove that the bright patches visible in Sentinel-1 SAR images are due to volume scattering from hydrometeors in the melting layer, we compare the SAR data with data from radar backscattering measurements from the melting layer carried out with ground-based and airborne radars. For this comparison, we employ the parameters LDR and LDRsAR, where LDR denotes the Depolarization Ratio, defined by Eq. 3, which is used by radar meteorologists to localize the melting layer, and LDRsAR, which we define by:

$\operatorname{LDR}_{\mathrm{SAR}}=10 \log _{10}\left(\sigma_{\mathrm{VH}}^{\text {total }} / \sigma_{\mathrm{VV}}^{\text {total }}\right) \quad$ or $\quad \operatorname{LDR}_{\mathrm{SAR}}=10 \log _{10}\left(\sigma_{\mathrm{HV}}^{\text {total }} / \sigma_{\mathrm{H}}^{\text {total }}\right)$

Here $\sigma^{\text {total }}$ denotes the sum of the NRCS due to volume scattering, $\sigma^{\text {volume }}$, and the NRCS due to surface scattering, $\sigma^{\text {surface }}$ :

$$
\sigma^{\text {total }}=\sigma^{\text {surface }}+\sigma^{\text {volume }}
$$

The subscripts denote the polarizations for transmission in analogy to the definition of LDR (Eq. 3). When calculating $\sigma^{\text {total }}$ from the backscattering data, one has to correct for the attenuation of the radar pulse when it propagates through the melting layer and through the layer above containing frozen hydrometeors (-snowflakes) and the layer below containing liquid hydrometeors (rain drops)y. However, while for X-band, attenuation is a major effect (see, e. g., Danklmayer et al., 2009), it is a minor effect for C-band as long as the rain rate is not too high $(<20 \mathrm{~mm} / \mathrm{h})$ (Tounadre and Morland, 1997). E.g., when using the empirical $\mathrm{aR}^{\mathbf{b}}$ relation of Olsen et al. (1998) for calculating the attenuation, one obtains for a $5 \mathrm{~km}$ thick rain cell with rain rate of $30 \mathrm{~mm} / \mathrm{h}$ an attenuation of $1.3 \mathrm{~dB}$. In this investigation, we neglect attenuation, since it has no effect on our result on the nature of the scattering mechanism.

In all Sentinel-1 SAR images presented in Figs, $5-8$, volume scattering is the dominant scattering mechanism in the bright patches. The contribution of surface scattering to the total scattering is particularly small in the events of 6 June 2018 (Fig. 5) and of 25 June 2019 (Fig. 


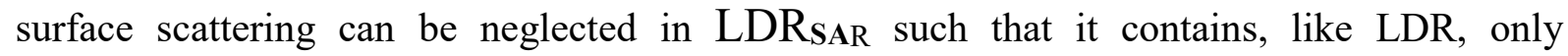
contributions from volume scattering, We now compare LDRsAR values measured in then bright patches with LDR values measured in radar backscattering from the melting layer by using ground-based and airborne radars. In these cases, LDRsar has peak values in the bright patches of $-12 \mathrm{db}$ and $-13 \mathrm{~dB}$, which compare well with LDR values characterizing the melting layer (see Section 2,3). Furthermore, the SIR-C/SAR data presented in Section 4 (Fig. 10 b) show LDRsAR values of $-15 \mathrm{~dB}$ and $-16 \mathrm{~dB}$ for horizontally and vertically polarized transmitted signals, respectively, which also lie in the range of LDR values characterizing radar backscatter from the melting layer as measured by ground-based and airborne radars. Thus. we conclude that the scattering mechanisms causing the bright patches in the SAR images and the high LDR values in radar backscattering measurements from the melting layer, must be the same, i.e., the scattering mechanism is volume scattering from wobbling, non-spherical, oblate hydrometeors within the melting layer.

\section{Summary and conclusions}

In this paper, we have provided evidence that the scattering mechanism causing the large radar backscatter values at co-and cross-polarization often observed in Sentinel-1 SAR images of the sea surface in the presence of rain ("bright patches") is scattering from wobbling, nonspherical, oblate hydrometeors within the melting layer. In the past, several other scattering mechanism have been proposed, which are all based on the modification of the sea surface roughness due to rain drops impinging onto the sea as described in the Introduction. In a recent review paper dealing with rain footprints on C-band SAR images of the ocean (Alpers et al., 534 2016), it was stated in the Conclusion section: "The scattering mechanism causing the bright patches in C-band, co-polarized SAR images of rain cells could not be determined". In this paper, we have identified the scattering mechanism by comparing Sentinel-1 co-and cross- 
polarization SAR data with data obtained from radar backscattering measurements from the melting layer carried out with ground-based and airborne radars. We have calculated the ratio of the NRCS values at co- and cross-polarization in the bright patches in the SAR images (LDRsAR) and compared them with the ratio of the radar reflectivity at cross-and co-polarization (LDR values) measured in radar backscattering experiments from the melting layer using ground-based and airborne radars. Since both ratios have similar values and since it is known that the last one (LDR) characterizes the melting layer, we conclude that the bright patches are caused by scattering from the melting layer. In this context, we would like to mention that such scattering mechanism was already suspected by Katsaros et al. (2000) who analyzed copolarized Radarsat-1 C-band data of the hurricane Danielle in 1998 and noticed small white spots within a rain cell, which they then compared them passive microwave data from the Special Sensor Microwave/Imager (SSM/I) onboard DMSP satellites. They suspected that the white spots result from "randomnly oriented ice particles in th cloud". We know of no paper in which this idea, i.e., the comparison of C-band SAR with passive microwave data, was pursued further.

When screening C-band co-polarization SAR images for radar signatures caused by scattering from the melting layer, one must be aware of the fact that they are sometimes distorted by overlapping radar signatures due to rain-induced surface scattering, as evident in the SIR-C/X-SAR CHH and CVV images (compared to the CHV image) shown in Fig. 9. This suggests that cross-polarization SAR images are better suited to detect radar signatures of the melting layer than co-polarization SAR images. Furthermore, we conclude from Fig.10 b that $\mathrm{HH}$ and HV C-band SAR images show similar characteristics of radar scattering from the melting layer as VV and VH SAR images The analysis of C-band co-and cross-polarization Sentinel-1 SAR images presented in this paper suggests the following semi-quantitative criterion for identifying areas on Sentinel-1 SAR images of the ocean surface as being caused 
562

563

564

565

566

567

568

569

570

571

572

573

574

575

576

577

578

579

580

581

582

583

by radar scattering from hydrometeors in the melting layer: VV NRCS must have values around $-10 \mathrm{~dB}$ or larger and VH NRCS values around $-20 \mathrm{~dB}$, such that LDRSAR has values between $-15 \mathrm{~dB}$ and $-10 \mathrm{~dB}$. We expect this criterion to be applicable for incidence angles between 30 and 70 degrees and for wind speeds below $20 \mathrm{~m} / \mathrm{s}$. The identication of areas in C-band SAR affected by scattering from the melting layer is of relevance for ocean surface wind retrieval using C-band SARs, since in these areas the conventional wind retrieval algorithm is not applicable.

\section{Acknowledgments}

This study was supported by ESA by the project: "Sentinel-1A Mission Performance Center for access of Sentinel-1 Interferometric Wide Swath data" and by the China Scholarship Council (CSC), who awarded a Ph. D. scholarship to Yuan Zhao. We are grateful to the colleagues in LOPS of IFREMER for their help in data acquisition and data processing and to Nicole Braun for providing Fig. 10. Last not least, we want to thank the three anonymous reviewers for their very valuable suggestions to improve the manuscript.

\section{References}

Alpers, W., Zhang, B., Mouche, A., Zeng, K., Chan, P.W., 2016. Rain footprints on C-band synthetic aperture radar images of the ocean - Revisited. Remote Sens. Environ. 187, 169-185. doi:10.1016/j.rse.2016.10.01516/j.rse.2016.10.015

Atlas, D. A., 1994a. Footprints of storms on the sea: a view from spaceborne synthetic aperture radar, J. Geophys. Res. 99, 7961-7969. doi:10.1029/94jc00250

Atlas, D. A., 1994b. Origin of storm footprints on the sea by synthetic aperture radar. Science 266, 13641366. doi:10.1126/science.266.5189.1364 
Bliven, L., Branger, H., Sobieski, P., Giovanangeli, J.-P., 1993. An analysis of scatterometer returns from a water surface agitated by artificial: evidence that ring-waves are the main feature. Int. J. Remote Sens. 14, 2315-2329. doi:10.1080/01431169308954039

Bliven, F., Sobieski, P.W., Craeye, C., 1997. Rain generated ring-waves: measurements and modelling for remote sensing. Int. J. Remote Sens. 18, 221-228. doi: 10.1080/014311697219385

Boodoo, S., Hudak, D., Donaldson, N., Leduc, M., 2010. Application of dual-polarization radar meltinglayer detection algorithm. J. Appl. Meteorol. Climatol. 49, 1779-1793. doi:10.1175/2010jamc2421.1

Brandes, E.A., Ikeda, K., 2004. Freezing-level estimation with polarimetric radar. J. Appl. Meteor. 43, 1541-1553. doi:10.1175/jam2155.1

Braun, N., 2003, Untersuchungen zur Radar-Rückstreuung und Wellendämpfung beregneter Wasserober flächen. Ph.D. thesis, University of Hamburg, Germany, Shaker Verlag, Aachen, Germany.

Braun, N., Gade, M., 2006. Multifrequency scatterometer measurements on water surfaces agitated by artificial and natural rain, Int. J. Remote Sens. 27, 27-39. doi: 10.1080/01431160500239214

Browne, I.C., Robinson, N.P., 1952. Cross-polarization of the radar melting-band. Nature 170, 10781079.

Contreras, R.F., Plant, W.J., 2006. Surface effect of rain on microwave backscatter from the ocean: Measurements and modeling. J. Geophys. Res., Oceans 111(C8). doi:10.1029/2005JC003356

D'Amico, M.M., Holt, A.R., Capsoni, C., 1998. An anisotropic model of the melting layer. Radio Sci. 33, 535-552. doi: 10.1029/97rs03049

Danklmayer, A., Döring, B.J., Schwerdt, M., Chandra, M., 2009. Assessment of atmospheric propagation effects in SAR images. IEEE Trans. Geosci. Remote Sens. 47, 3507-3518. doi: 10.1109/TGRS.2009.2022271 
Dissanayake, A. W., McEvans, N. J., 1978. Radar and attenuation properties of rain and bright band. IEEE Conf. Publ. 169, 125-129

Hwang, P., Stoffelen, A. A., van Zadelhoff, G.-J., Perrie, W., Zhang, B., Li, H., Shen, H., 2015. Crosspolarization geophysical model function for C-band radar backscattering from the ocean surface and wind speed retrieval, J. Geophys. Res. Oceans, 120, 893-909. doi:10.1002/2014JC010439

Houze, R. A., 2014. Cloud Dynamics, International Geophysics, vol, 104, Elvesier, Amsterdam, ISBN: 9780123742667

Jameson, A.R., 1989. The interpretation and meteorological application of radar backscatter amplitude ratios at linear polarizations. J. Atmos. Oceanic Technol. 6, 908-919. doi:10.1175/15200426(1989)006<0908:tiamao $>2.0 . c 0 ; 2$

Jameson, A. R., Li, F. K., Durden, S. L., Haddad, Z. S., Holt, B., Fogarty, T., Im, E., Moore, R. K., 1997. SIR-C/X-SAR observations of rain storms. Remote Sens. Environ. 59, 267-279. doi:10.1016/s0034-4257(96)00159-9.

Katsaros, K. B., Vachon, P. W., Black, P.O., Dodge, P.P., Uhlmann, E.W., 2000. Wind Fields from SAR: Could They Improve Our Understanding of Storm Dynamics? JOHNS HOPKINS APL TECHNICAL DIGEST, VOLUME 21, NUMBER 1, 86-93.

Kumjian, M. R., 2013. Principles and applications of dual-polarization weather radar. Part I: Description of the polarimetric radar variables. J. Operational Meteor. 1, 226-242. doi: 10.15191/nwajom.2013.0119

Melsheimer, C., Alpers, W., Gade, M., 1998. Investigation of multifrequency/multipolarization radar signatures of rain cells over the ocean using SIR-CX-SAR data. J. Geophys. Res. 103, 1886718884. doi:10.1029/98JC00779Nie, C., Long, D.G., 2007. A C-band wind/rain backscatter model. IEEE Trans. Geosci. Remote Sens. 45, 621-631. doi:10.1109/TGRS.2006.888457

Oguchi, T., 1983. Electromagnetic wave propagation and scattering in rain and other hydrometeors, Proc. IEEE 71, 1029-1078. doi:10.1109/proc.1983.12724 
Olsen, R., Rogers, D.V., Hodge, D., 1978. The ar b relation in the calculation of rain attenuation. IEEE Transactions on antennas and propagation 26, 318-329. doi:10.1109/TAP.1978.1141845.

Ryzhkov, A.V., 2001. Interpretation of polarimetric radar covariance matrix for meteorological scatterers: Theoretical analysis. J. Atmos. Oceanic Technol. 18, 315-328. doi:10.1175/15200426(2001)018<0315:ioprcm>2.0.co

Szyrmer, W., Zawadzki, I.,1999. Modeling of the melting layer. Part I: Dynamics and microphysics. J. Atmos. Sci. 56, 3573-3592. doi:10.1175/1520-0469(1999)056<3573:motmlp>2.0.co;2

Tournadre, J., Morland, J.C., 1997. The effects of rain on Topex/Poseidon altimeter data. IEEE Trans. Geosci. Remote Sens. 35, 1117-1135. doi:10.1109/36.628780Wijesekera, H.W., Gregg, M.C., 1996. Surface layer response to weak winds, westerly bursts, and rain squalls in the western Pacific Warm Pool. J. Geophys. Res. 101, 977-997. doi:10.1029/95JC02553

Willis, P.T., Heymsfield, A.J., 1989. Structure of the melting layer in mesoscale convective system stratiform precipitation. J. Atm. Sci. 46, 2008-2025

Zhang, G., Li, X., Perrie, W., Zhang, B., Wang, L., 2016. Rain effects on the hurricane observations over the ocean by C-band synthetic aperture radar. J. Geophys. Res., Oceans 121, 14-26. doi:10.1002/2015JC011044. 